UDC $314.93,316.462$

LBC 60.7, 60.54

\title{
THE PHENOMENON OF GERONTOCRACY IN PUBLIC ADMINISTRATION: THE DICHOTOMY OF "OPEN" AND "CLOSED" SOCIAL AND POLITICAL SYSTEMS ${ }^{1}$
}

\author{
Elena M. Drinova \\ Volgograd State University, Volgograd, Russian Federation \\ Sergey I. Morozov \\ Volgograd State University, Volgograd, Russian Federation
}

\begin{abstract}
The archetype of a gerontocrat manifests itself in society regardless of the time, era, level of political and economic development of the state. In traditional societies, the archetype of the gerontocrat is stipulated by religious traditions, not significant development of the system of social and political communication and transfer of intergenerational experience; in modern societies, local manifestations and topoi of gerontocracy are generated by demographic and socio-political challenges facing national states, what generates numerous threats and risks to the development of the public-political sphere. This is correlated with the cultural and genetic code transmitted from generation to generation in the process of socialization of an individual. Among the representatives of post-traditional societies the manifestation of the archetype of the gerontocrat takes place at the level of the collective unconscious, but it can consciously explain their own "gerontocrat-oriented" models of political behavior. Gerontocrats have been in power for a long time, forming in society the idea of this activity as an exclusively "professional" related to the knowledge and experience accumulated by the advanced age. Within such a political "coordinate system" the risk of falling economic growth increases, the economic crisis, the devaluation of the national currency, high levels of corruption, hunger and poverty. The institutional characteristics of the topos of the gerontocracy are the following: the highest power authorities in the state are concentrated in the hands of a legally elected small group of the establishment individually determining the priorities of foreign and domestic policy. The long-term presence of such leaders in power forms the so-called political cohort of gerontocrats. In the twentieth century the topos of gerontocracy was characteristic of the state-political system of the USSR. At the beginning of the XXI century the topos of gerontocracy remains in the political process of a number of African countries. However, the phenomenon of the gerontocrat can manifest itself in modern Western countries. As a result, among the basic values of the ruling elites, conservatism, religiosity (desecularization), and etatism come to the fore.
\end{abstract}

Key words: gerontocracy, archetype, topos, public policy, political threats, demography, establishment.

УДК $314.93,316.462$

ББК $60.7,60.54$

\section{ФЕНОМЕН ГЕРОНТОКРАТИИ В ПУБЛИЧНОМ УПРАВЛЕНИИ: ДИХОТОМИЯ «ОТКРЫТЫХ» И «ЗАКРЫТЫХ» СОЦИАЛЬНО-ПОЛИТИЧЕСКИХ СИСТЕМ ${ }^{1}$}

\author{
Елена Михайловна Дринова \\ Волгоградский государственный университет, г. Волгоград, Российская Федерация \\ Сергей Иванович Морозов \\ Волгоградский государственный университет, г. Волгоград, Российская Федерация
}


Аннотация. Архетип геронтократа проявляется в обществе независимо от времени, эпохи, уровня политического и экономического развития государства. В традиционных обществах архетип геронтократа обусловлен религиозными традициями, незначительным развитием системы социально-политической коммуникации и передачи межпоколенческого опыта; в современных обществах локальные проявления и топосы геронтократии порождаются демографическими и общественно-политическими вызовами, стоящими перед национальными государствами, что генерирует многочисленные угрозы и риски для развития публично-политической сферы. Это связано с культурно-генетическим кодом, передающимся от поколения к поколению в процессе социализации индивида. У представителей посттрадиционных обществ проявление архетипа геронтократа происходит на уровне коллективного бессознательного, однако они могут осознанно объяснить собственные «геронтократоориентированные» модели политического поведения. Геронтократы длительное время находятся у власти, формируя в обществе представления о данной деятельности как об исключительно «профессиональной», связанной с накопленными к преклонному возрасту знаниями и опытом. В подобной политической «системе координат» увеличивается риск падения темпов экономического роста, экономического кризиса, девальвации национальной валюты, высок уровень коррупции, голода и нищеты. Институциональные характеристики топоса геронтократии проявляются тогда, когда высшие властные полномочия в государстве сконцентрированы в руках законно избранной небольшой группы правящей элиты, единолично определяющей приоритеты внешней и внутренней политики. Длительное нахождение у власти подобных руководителей государств формирует так называемую политическую когорту геронтократов. В XX в. топос геронтократии был характерен государственно-политической системе СССР. В начале XXI в. в политическом процессе ряда африканских стран сохраняется топос геронтократии. Однако феномен геронтократа может проявляться и в современных западных странах. В результате на первый план среди базовых ценностей правящих элит выдвигаются консерватизм, религиозность (десекуляризация), этатизм.

Ключевые слова: геронтократия, архетип, топос, публичная политика, политические угрозы, демография, правящая элита.

Трендом современного общества выступает глобальное старение населения [4]. В мире и, в частности, в странах Западной Европы происходит стремительное увеличение доли пожилых людей. Если в 2017 г. их численность составляла 962 млн человек, то согласно долгосрочному прогнозу через 30 лет будет более 2 млрд человек. Вместе с тем численность населения в этих странах за последующие годы сократится на 15 \% [21]. В то время как демографическая группа, чей возраст составляет от 60 лет и старше, демонстрирует тенденцию быстрого роста. Эволюционный характер старения населения сопровождается не только глобальными демографическими трансформациями в странах ЕC, Азии, Северной Америки, но и изменениями в сфере публичной политики.

Как отмечают Ф.М. Торрес-Гил и К. Спенсер-Суарес, продолжающееся увеличение жизни в развитых странах сопровождается снижением уровня рождаемости, что соответственно требует новых подходов к проведению государственной пенсионной политики, нормой которой становятся межпоколенные компромиссы [18, с. 230]. Кроме того, нормой является фактическое увеличение возраста «вхождения» в сферу официального поли- тического участия. Х.-В. Синн считает, что демографический кризис требует фундаментальных реформ в пенсионной системе, в противном случае геронтократия может стать нормой в XXI в. [17, с. 156]. В результате в наше время достаточно наглядно повторяется ситуация времен античной Греции, в которой высшими органами публично-политического управления выступали Ареопаг и Гелиэя, формировавшиеся преимущественно из представителей «возрастных» демографических групп.

В общественных науках существует несколько вариантов решения данной проблемы. По мнению политических геронтологов, увеличение продолжительности жизни означает, что пожилые люди более длительное время могут вести здоровую продуктивную жизнь, использовать свой интеллектуальный потенциал, тем самым не только возвращая государству доход от инвестиций в людей, но и обеспечивая широкое представительство в публично-политической сфере. К.М. Воключ обращает внимание: при проведении государственной политики целесообразно учитывать тот факт, что в государстве всеобщего благосостояния существует низкий риск заболеваний и инвалидности, в то время как дискри- 
минация по возрасту представляет значительный риск для здоровья пожилых людей. Более того, активная жизненная позиция пожилых граждан способствует сохранению их высоких психической и физической функций. Соответственно производственная деятельность пожилых оплачивается, либо они занимаются волонтерской работой [19].

Как отмечает К. Комп, стареющее население имеет возможность оказывать конструктивное влияние на государство всеобщего благосостояния. Эта демографическая группа занимается такой продуктивной деятельностью, как добровольческая и неформальная помощь, что способствует повышению уровня благосостояния в стране. Соответственно стареющее население следует рассматривать как один из ресурсов для государства всеобщего благосостояния [14, c. 53]. Следует отметить, что в ряде развивающихся стран, а также в России добровольческая и волонтерская деятельность граждан старших возрастных когорт становится приоритетным направлением развития государственной социальной политики. Институционализация волонтерского движения в структуре гражданского общества служит одним из важнейших ресурсов развития публичной политики и государства всеобщего благосостояния.

Отметим, что чем выше уровень социального и экономического развития в стране, тем более активной и успешной становится политическая, экономическая и социальная жизнь пожилых граждан. Вместе с тем ожидаемое увеличение продолжительности жизни граждан не всегда означает, что в реальности будет иметь место возможная продолжительность здоровой жизни. Неблагоприятные последствия старения обусловлены неравенством доходов, что сказывается на уровне и качестве жизни пожилых граждан. Данные риски следует рассматривать в контексте дополнительного финансового бремени для межбюджетных отношений в стране. Следует отметить наличие и определенных политических рисков. Опасность, с которой сталкиваются общества со стремительно растущим пожилым населением, проявляется в том, что пожилые избиратели блокируют необходимые реформы, что приводит к конфликту между властью геронтократов и молодым поколением (см., например, публично-политические обсуждения вопросов повышения пенсионного возраста в странах Восточной Европы). По мнению М. Коли и К. Арза, общей тенденцией западноевропейских стран является проведение пенсионной реформы, основной целью которой выступает первостепенная защита доходов пенсионеров. Авторы отмечают, что готовность граждан платить налоги на содержание пожилых граждан по-прежнему сильно различается среди национальных государств [13, с. 251-264].

Иной точки зрения придерживаются сторонники неолиберальных ценностей. По их мнению, возрастание доли пожилого населения неминуемо приведет к кризису государства всеобщего благосостояния. В результате произойдет сокращение благосостояния, что приведет к структурной трансформации самого государства. Увеличение доли пожилых граждан сопровождается уменьшением численности населения трудоспособного возраста, возрастают требования к системам пенсионного обеспечения и здравоохранения, что в свою очередь требует увеличения объема доходов государства благосостояния. Соответственно, чем выше продолжительность жизни граждан, тем более вероятны риски в социально-политической сфере. Как следствие - необходимость постоянного увеличения бюджетных трансфертов на поддержание достойного существования пожилых граждан, увеличение качества жизни данных слоев населения. Соответственно социальные программы, направленные на увеличение качества жизни других возрастных когорт, в частности молодежи, постепенно должны сокращаться. Как отмечают В. Ателла и Л. Карбонари, государственный ущерб, причиненный геронтократией, обусловливается долговременным отсутствием отдачи от инвестиций в человеческий капитал пожилых граждан. Coответственно в ряде западноевропейских стран имеет место тенденция к недоинвестированию в государственные пенсионные программы [9].

А.Л. Бовенберг обращает внимание на тот факт, что происходит уменьшение доли поколения среднего возраста, которое ухаживает за пожилыми людьми. Данный вид дея- 
тельности все чаще рассматривается средневозрастной когортой как «обязательство, либо тяжкая ноша», которую необходимо выполнять, а отнюдь не как работа, направленная на сохранение пожилых людей в качестве ресурса, жизненно важного для государства. Увеличивающаяся налоговая нагрузка на малочисленное поколение «среднего возраста» представляет серьезную угрозу социальной солидарности в обществе. Гражданское доверие к стабильному общественному порядку, в котором правительство сдерживает свои обязательства, может быть разрушено, что порождает политические потрясения [11, c. 60]. Соответственно демографические риски продуцируют социальные, экономические и политические риски. Яркими примерами тому могут служить: обсуждение в публично-политическом пространстве введения налога на «тунеядство»; отмена индексаций пособий по материнству и детству; увеличение сроков продолжительности «молодежного» возраста и многое другое. В этом случае возникает конфликт между политической властью старших поколений (которые зависят от государственных трансфертов и не склонны к риску) и экономической мощью младшего поколения, а также среднего, работающего населения (которое контролирует основной дефицитный ресурс, подпитывающий современную наукоемкую и инновационную экономику). В связи со сказанным возникает ряд вопросов: каковы последствия усиления геронтократии в современном мире? Какое влияние оказывает геронтократия на сферу публичной политики и функционирование политических систем?

Гипотеза исследования: в традиционных обществах архетип геронтократа обусловлен, прежде всего, религиозными традициями, незначительным развитием системы социальнополитической коммуникации и передачи межпоколенческого опыта; в посттрадиционных обществах локальные проявления и топосы геронтократии порождаются демографическими и общественно-политическими вызовами, стоящими перед национальными государствами, что генерирует многочисленные угрозы и риски для развития публично-политической сферы.

Операционализация категории «геронтократия» определяется методологией иссле- дования. Согласно М. Веберу, геронтократия понимается как форма господства в обществе, осуществляющаяся старейшими, которые выступают адептами священной традиции [20, p. 231-233]. Содержательная сторона геронтократии раскрывается в контексте традиционного господства. Его легитимация детерминирована сакральной традицией, властными полномочиями. В традиционных обществах геронтократия основывается на базовой модели воспитания; иерархия власти выстраивается, исходя из личной преданности подчиненных. Выделение ее субъектного измерения обусловлено отсутствием административного аппарата управления, что характерно для патриархального строя.

В традиционных обществах геронтократия - это особый тип взаимодействия, основанный на добровольном подчинении властвующему субъекту, обладающему сакральной харизмой. Иерархия власти формируется в рамках традиции, а не согласно установленным в обществе правилам, нормам и формальным принципам управления. М. Вебер разграничивает понятие «геронтократия», как власть старейших; традиционное господство, где вертикаль властных отношений детерминирована личными отношениями; наследственная власть. Критерием классификации в данном случае выступает форма легитимного господства $[20$, с. 557]. Близкой точки зрения придерживаются А.Б. Паласиос Гамаз, С.Ф. Кордова и С.В. Бенитес. Как отмечают авторы, принципы управления геронтократии основаны на опыте старейшин. В традиционном религиозном обществе образ геронтократа ассоциирует с властью, лидерством, уважением, престижем. Совет старейшин - геронтократы - сохраняет и транслирует обычаи и традиции, связанные в основном с опытом постижения сакрального [15, с. 10].

Генезис геронтократии анализируется сквозь призму мифологии, архетипов бессознательного в традиционных и посттрадиционных обществах. Согласно К.Г. Юнгу, основание геронтократии восходит к архетипам бессознательного. Онтология архетипа самости вбирает в себя все формы: от трансцендентной, божественной до материально проявленной, земной, соответственно, «от высочайшей до нижайшей» [8, с. 255]. В гностической ин- 
терпретации самость проявляется в четвертичном символе целостности - кватернионе Моисея. Именно в нем Антропос (высший Адам) соответствует духовной субстанции и синонимичен физическому и духовному отцу Иофору; соответственно низший Адам смертному человеку. Зиппора выступает как высшая мать Ева и одновременно как обычная женщина. Моисей представляет архетипип «мудрого старца» [8, с. 257-258]. Основываясь на данной концепции, мы приходим к следующим положениям: символика архетипа геронтократа восходит к архетипу самости К.Г. Юнга. Моисей, обладая всей полнотой власти, данной ему Богом, представляет собой изначальный тип геронтократа. Реализация его властных полномочий основывается на божественных трансцендентных/имманентных ценностях. Руководствуясь концептом К.Г. Юнга «Aion - феноменология самости», мы определяем архетип геронтократа как образ/проекцию Моисея, харизматического лидера, проявленного в символике самости.

На ранних стадиях развития традиционных обществ авторитет возраста (геронтократа) был абсолютным. Первобытные религии и культ предков способствовали укреплению власти старейшин. Формирование политического в традиционном обществе сопровождалось возрастанием роли вождя, что, соответственно, приводило к ослаблению контроля со стороны старейших. Со временем их власть становилась номинальной, реальный контроль за властными полномочиями переходил к аппарату управления правителя [1, с. 127].

В древних цивилизациях существовала развитая система геронтократии. В городахполисах Древней Греции функционировали органы власти, возглавляемые геронтами, пожилыми политиками [12, с. 83]. Высшим органом государственной власти в греческом городе-полисе было Народное собрание, которое занималось решением внешнеполитических, внутриполитических и общественных проблем. Одновременно с Народным собранием в городе-полисе действовал Совет старейшин. В Спарте в Совет старейшин входило 28 граждан, достигших возраста 60 лет, свою должность они занимали пожизненно. Совет старейшин являлся высшим органом правления, органом законодательной власти. Только его члены - геронты - обладали правом законодательной инициативы. Совет старейшин обладал полной автономией, его не контролировал ни один орган власти. В иерархии государственной власти города-полиса Спарты Совет старейшин занимал главенствующее место. Привилегией геронтов было право отменять решения Народного собрания. Античная демократия закрепила профессионализм в политической сфере, создала почву для трансляции геронтократических традиций в обществе. В Древней Греции был сформирован демократический режим, основу которого составляли принципы выборности, гласности, свободы слова [3, с. 442].

Геронтократические традиции сохранились в средневековых цивилизациях. Классическим примером геронтократии была Венецианская республика, существовавшая в IVXVIII века. В ней на протяжении более тысячи лет властными полномочиями обладали дожи - пожилые правители. Дожи избирались публично и занимали свою должность пожизненно. В конце XIV в. в Венецианской республике сложилась легитимная политическая система геронтократии, которая просуществовала до конца XVIII века. Со временем власть дожей становилась номинальной, впоследствии были сформированы новые государственные структуры, которые выполняли часть полномочий дожей, в том числе и в публично-политической сфере.

В эпоху Возрождения происходит формирование новой антропоцентричной парадигмы, которая вытесняет предыдущую теоцентрическую. Доминирующими становятся принципы гедонизма, антропоцентризма; получает распространение культ красоты человеческого тела. С началом Нового времени и переходом к индустриальному типу хозяйственноэкономических и общественно-политических отношений происходит постепенное угасание геронтократической традиции. Модернизация охватывает все сферы социальных и политических отношений, активное развитие получают прикладные отрасли научного знания, ориентированные на рыночные модели капиталистических отношений, обеспечение прав собственности. В результате данных процессов в обществе постепенно формируется иное 
отношение к феномену старости. Уже с конца XVII в. начинается строительство домов престарелых, ориентированных на продление сроков жизни представителей возрастных групп населения. В это же время появляются соответствующие научные теории, обосновывающие необходимость назначения государственных пенсий по старости.

Однако, как отмечает Л.С. Выгодский, образцы поведения, характерные для традиционных типов общества, могут воспроизводиться и в поведении человека посттрадиционного общества [2, с. 58]. Это связано с культурно-генетическим кодом, передающимся от поколения к поколению в процессе социализации индивида. Проявляются данные феномены в сюжетах детской литературы, социально-одобряемых образцах поведения в отношении старшего поколения, усваиваемых молодым поколением по мере затягивающегося процесса взросления. Соответственно архетип геронтократа проявляется в обществе независимо от времени, эпохи, уровня политического и экономического развития государства.

В индустриальном обществе XX в. продолжал сохраняться и реформироваться топос геронтократии. В числе институциональных характеристик данного топоса выделим следующие: высшие властные полномочия в государстве сконцентрированы в руках законно избранной небольшой группы правящей элиты (геронтократов), которая единолично определяет приоритеты внешней и внутренней политики. Геронтократы длительное время находятся у власти, формируя в обществе представления о данной деятельности как об исключительно «профессиональной», связанной с накопленными к преклонному возрасту знаниями и опытом. В связи с этим средний возраст правящих элит имеет тенденцию достижения «запенсионных» значений, руководящие посты фактически становятся «пожизненными» и освобождаются в связи со смертью геронтократа. Рекрутирование элиты происходит за счет преданных возрастных членов партий и близких общественно-политических движений, которые разделяют преимущественно традиционные и консервативные ценности. Воспроизводство геронтократических традиций в обществе может даже закрепляться законодательно, например, путем внесения изменений в Основной закон страны положения о «пожизненном статусе лидера нации».

Как отмечает Б.Ф. Поршнев, данная ситуация может объясняться тем фактом, что «известная доля бессознательного поведения присуща представителям современных индустриальных обществ... Индивид сталкивается в ходе своей жизнедеятельности с определенным набором стандартных ситуаций, что избавляет его от необходимости затрачивать интеллектуальные усилия для нахождения оптимального поведения» [7, с. 33-34]. Следовательно, у индивидов-представителей посттрадиционных обществ проявление архетипа геронтократа происходит на уровне коллективного бессознательного, однако они могут осознанно объяснить собственные «геронтократоориентированные» модели политического поведения. Примером существования топоса геронтократии либо его локальных проявлений в XX в. могут служить практики геронтократии в Советском Союзе, ряде стран Восточной Европы и Африканского континента.

В XX в. и начале XXI в. в политическом процессе ряда африканских стран ключевую роль играли (или до сих пор играют) традиционные структуры власти, вождизм. В то же время, несмотря на созданные в политических системах по западному образцу институты демократии и парламентаризма, сохранились и продолжают воспроизводиться местные клановые традиции [14, с. 225]. В ряде африканских стран продолжает существовать топос геронтократии. Одним из старейших правителей на Африканском континенте был президент Зимбабве Р. Мугабе (правил страной в возрасте 63-93 лет). Чтобы оставаться у власти, он трижды изменял конституцию страны, однако за время его правления Зимбабве превратилась в одну из самых беднейших стран мира. Результатами правления геронтократии в Зимбабве стали экономический кризис, девальвация национальной валюты, высокий уровень коррупции, голод и нищета.

О.Х. Ахмед аль-Башир (74 года) одержал очередную победу на выборах президента Судана в 2015 году. Однако он является фактическим руководителем страны с 1989 года. Следует особо отметить, что Аль-Башир - 
первый президент, против которого Международным уголовным судом были выдвинуты обвинения в убийстве гражданских лиц, массовых изнасилованиях, геноциде населения. Как отмечают И. Ванасика, Дж.П. Хауэлл, Р. Литтрелл и П. Дорфман, в странах Африканского континента, которые находятся к югу от Сахары, именно негативное наследие колониального господства способствовало развитию практик трайбализма, вождизма и коррупции. Логическим итогом данных практик стали ориентации населения на харизматический тип лидерства, а также высокий уровень групповой солидарности и патернализм [16]. Естественно, что в подобных условиях возможности развития транспарентных практик властвования и господства, обеспечения публичности политической деятельности, в противовес доминирования топоса геронтократии, в странах Африканского континента значительно ограничены.

Однако феномен геронтократа может проявляться и в странах «западной демократии». Так, например, в Соединенном Королевстве Великобритании и Северной Ирландии должности премьер-министра и членов кабинета правительства традиционно занимали не только преимущественно представители аристократической элиты страны, но и лица «старших возрастных когорт». Одним из старейших и авторитетнейших политических деятелей $\mathrm{XX}$ в. был премьер-министр Великобритании У. Черчилль. В возрасте 66 лет он впервые был назначен на эту должность, которую с перерывом занимал до 81 года. Не меньшее распространениелокальных проявлений геронтократии присуще и Французской Республике (президенты Франции Ш. де Голль, Ж. Помпиду). В предвыборной президентской кампании в США 2016 г. активное участие приняли кандидаты Х. Клинтон (69 лет) и Д. Трамп (70 лет). В результате впервые в истории этой страны президентом был избран 70-летний политик [6].

Топос геронтократии длительное время был характерен для государственно-политической системы СССР. В наиболее авторитетный властно-политический институт - Политбюро ЦК КПСС - входили 20-25 человек, которые одновременно занимали высшие государственные посты. В 1980 г., во время правления
Л.И. Брежнева, в разгар эпохи застоя, период упадка аграрной промышленности, увеличивающегося технологического отставания от передовых западных держав, в состав Политбюро входили: А.П. Кириленко (74 года), А.А. Громыко (71 год), А.Н. Косыгин (76 лет), А.Я. Пельше (81 год), Н.В. Подгорный (77 лет), М.А. Суслов (78 лет), Д.Ф. Устинов (72 года). Своеобразным «исключением» был будущий лидер Советского Союза Ю.В. Андропов (66 лет). Как правило, члены Политбюро занимали свой пост пожизненно, что подтверждают примеры Л.И. Брежнева, Ю.В. Андропова, К.У. Черненко. Похороны советских геронтократов сопровождались всесоюзным трауром и почетным захоронением в особом месте у Кремлевской стены. Важно подчеркнуть, что данный коллегиальный орган геронтократов принимал решения, касающиеся всех сторон жизни общества: хозяйственно-экономической стратегии развития страны, распространения государственно-политической идеологии, приоритетов внешней и внутренней политики. Не менее важным и очевидным представляется тот факт, что в подобной политической «системе координат» совершенно не оказалось места инструментам публичной политики и «инакомыслию». Отклонения от данной политической линии пресекались всей мощью идеологической пропаганды и государственно-партийного аппарата. Результатом данного политического режима стало падение в этот период темпов экономического роста в стране до 3-4 \% ВВП в год [5, с. 20]. Правление геронтократии в СССР, отсутствие существенных реформ (несмотря на усилия Ю.В. Андропова и М.С. Горбачева) привели к тотальному кризису, охватившему экономическую и политическую сферы советского общества, к распаду Советского Союза.

Не менее жизнеспособным топос геронтократии оказался и на территории государств постсоветского пространства, в рамках «демократических» практик формирования «национальных» авторитарных политических режимов. В Узбекистане бессменным руководителем среднеазиатской республики начиная с 1990 г. был И. Каримов (умер в 2016 г. в возрасте 78 лет). В Азербайджане с 1993 г. по 2003 г. (также до своей смерти в возрасте 80 лет) у власти находился глава республики 
Г. Алиев. Впоследствии президентом Азербайджана был избран его сын - И. Алиев, который успешно переизбирался на этот пост в 2008, 2013 и 2018 годах. В Республике Беларусь с 1994 г. по настоящее время бессменным президентом является А.Г. Лукашенко. И несмотря на то, что в 2018 г. ему исполнилось 64 года, есть основания полагать, что руководить республикой он также планирует еще продолжительное время с последующей конституционной передачей власти (пусть и не с полномочиями главы государства) своему сыну.

М. Бертон и Р. Панел, основываясь на подобных эмпирических данных, приходят к следующему выводу: в «закрытых» социально-политических системах лидеры государства не могут быть легко отстранены от должности законным путем, так как в большинстве авторитарных режимов не существует институционального способа увольнения некомпетентных геронтократов [10]. Солидаризируясь с авторами, полагаем возможным расширить данный тезис: в том числе и в современных западных странах, а также в постсоветских странах нелиберальных демократий прослеживается тенденция к распространению топоса геронтократии. Политические лидеры, законно пришедшие к власти, активно используют как легитимные (например, регулярное участие в парламентских выборах бывшего председателя Совета министров Италии С. Берлускони, попытки участия в президентских выборах экс-президента Франции Н. Саркози в 2017 г. и т. п.), так и не вполне легитимные механизмы сохранения и укрепления своих полномочий (регулярные внесения поправок в конституции бывших советских республик об изменении сроков и полномочий глав государств).

Таким образом, длительное нахождение у власти подобных руководителей государств формирует так называемую политическую когорту геронтократов. В результате на первый план среди базовых ценностей правящих элит выдвигаются консерватизм, религиозность (десекуляризация), этатизм. Однако, как заметил один из известнейших президентов США Дж. Кеннеди, «правительство, которое делает смену власти невозможной, делает революцию неизбежной». В «закрытых» со- циально-политических системах, формирующихся при авторитарных геронтократических режимах, несмотря на наличие протестных настроений политическая оппозиция обречена терпеть неудачи на парламентских и президентских выборах, поскольку пространство публичной политики чрезвычайно сужено или вовсе отсутствует.

В заключение отметим, что в современных западных демократиях в начале XXI в. активное участие пожилой политической элиты в социально-политическом процессе обусловлено в первую очередь качеством человеческого капитала и ростом продолжительности жизни. Локальные проявления геронтократии формально могут быть ограничены количеством сроков нахождения на высших государственных должностях. Вместе с тем следует отметить следующие риски геронтократии в «открытых» социально-политических системах стран «либеральных демократий»: сложности создания коалиции при формировании правительства, турбулентность в политической жизни, «авторитарные» императивы внешней политики, негативный образ политика в общественном мнении [8]. Тем не менее формы геронтократии в современном социально-политическом процессе, топос либо локальные проявления, зависят от объективных и субъективных факторов. К числу объективных факторов относится общее старение населения и возрастание доли пожилых политиков, к субъективным факторам следует отнести личностные характеристики политика, феномен мессианства, а также изменение транспарентных и соревновательных «правил» игры в политике.

\section{ПРИМЕЧАНИЕ}

${ }^{1}$ Исследование выполнено при финансовой поддержке РФФИ и Администрации Волгоградской области, проект «Стратегии, инновационные технологии институционализации и функционирования публичной политики в Волгоградском регионе» № 17-13-34039.

\section{СПИСОК ЛИТЕРАТУРЫ}

1. Бочаров, В. В. Власть. Традиции. Управление (попытка этисторического анализа политичес- 
ких культур современных государств Тропической Африк) / В. В. Бочаров. - М. : Наука, 1991. - 296 с.

2. Выгодский, Л. С. Детская психология / Л. С. Выгодский // Собр. соч.: в 6 т. - М. : Педагогика, 1984. - Т. 4. - 432 с.

3. Гиро, П. Частная и общественная жизнь греков / П. Гиро. -Петроград : Издание т-ва О. Н. Поляковой, 1915. - 687 c.

4. Декларация по проблемам старения. Доклад Всемирной ассамблеи по проблемам старения, Вена, 26 июля - 6 августа 1982 года (Издание Организации Объединенных Наций), глава VI. - Электрон. текстовые дан. - Режим доступа: http://www. un.org/ru/documents/decl_conv/declarations/declold. shtml (дата обращения: 10.03.2018). - Загл. с экрана.

5. Милюков, А. И. Опыт и уроки экономических реформ в СССР в 79-80-е годы / А. И. Милюков // Гуманитарные науки. Вестник Финансового университета. - 2018. - № 2. - С. 17-24.

6. Понамарева, Е. В. Репрезентация образа Дональда Трампа в британских медиатекстах политической направленности / Е. В. Понамарева // Филологические науки. Вопросы теории и практики. 2017. - № 10. - С. 143-147.

7. Поршнев, Б. Ф. Социальная психология и история / Б. Ф. Поршнев. - М. : Наука, 1979. - 235 с.

8. Юнг, К. Г. Исследование феноменологии самости. Aion / К. Г. Юнг. - М. : Рефл-бук ; Ваклер, 1999. $-336 \mathrm{c}$.

9. Atella, V. Gerontocracy Harmful for Growth? A Comparative Study of Seven European Countries / V. Atella, L. Carbonari // Journal of Applied Economics, Universidad del CEMA. - 2017. № 20. - P. 141-168.

10. Berton, M. R. Strategic gerontocracy: why nondemocratic systems produce older leaders / M. R. Berton, S. Panel // Public Choice. - 2017. Vol. 171, № 3. - P. 409-427.

11. Bovenberg, A. L. Grey New World: Europe on the Road to Gerontocracy? / A. L. Bovenberg // CESifo Economic Studies. - 2008. - Vol. 54, № 1. - P. 55-72.

12. Gilleard, C. Old Age in Ancient Greece: Narratives of desire, narratives of disgust / C. Gilleard // Journal of Aging Studies. - 2007. - Vol. 21, № 1. P. 81-92.

13. Kohli, M. The Political Economy of Pension Reform in Europe / M. Kohli, C. Arza // Handbook of Aging and the Social Sciences. - N. Y. ; L. : Academic Press, 2011. - P. 251-264.

14. Komp, K. S. The Political Economy of the Third Age / K. S. Komp // Gerontology in the Era of the Third Age: Implications and Next Steps / K. S. Komp, D. C. Carr. -N. Y. : Springer, 2011.-P. 51-66.

15. La gerontocracia y el consejo de ancianos /L. R. Gomez,A. B. P. Gàmaz, S. F. Cordoba, B. S. Villasana // Península. - 2013. - Vol. 8, № 1.-P. 7-24.
16. Leadership and Culture in Sub-Saharan Africa / J. P. Wanasika, R. Howell, R. Littrell, R. Dorfman, P. Managerial // Journal of World Business. - 2011. Vol. 46, № 2. - P. 234-241.

17. Sinn, H.-W. Pensions and the path to gerontocracy in Germany / H.-W. Sinn // European Journal of Political Economy. - 2003. - Vol. 19, №. 1. P. 153-158.

18. Torres-Gil, F. M. Aging electorates and gerontocracy: The politics of aging in a global world / F. M. Torres-Gil, K. Spencer-Suarez // International Handbook on Ageong and Public Polici. - Oxford : University of Oxford Press ; Edward Elgar Publishing, 2014. - P. 227-241.

19. Vauclair, C.-M. Why Does National Income Inequality Make Older People Ill? / C.-M. Vauclair // The Journals of Gerontology: Series B, Psychological Sciences and Social Sciences. - DOI: https://doi.org/10.1093/geronb/gbv102 (date of access: 04.05.2018). - Title from screen.

20. Weber, M. Economy and Society. An Outline of Interpretive Sociology / M. Weber. - Los Angeles ; L. : University of California Press, 1978. -635 p.

21. World Population Prospects The 2017. Revision Key Findings and Advance Tables. Electronic text data. - Mode of access: https://esa. un.org/unpd/wpp/Publications/Files/WPP2017 KeyFindings (date of access: 03.03.2018). - Title from screen.

\section{REFERENCES}

1. Bocharov V.V. Vlast. Traditsii. Upravlenie (popytka etistoricheskogo analiza politicheskikh kultur sovremennykh gosudarstv Tropicheskoy Afrik) [ Power. Traditions. Management (an attempt of an ethical analysis of the political cultures of modern states of Tropical Africa)]. Moscow, Nauka Publ., 1991. 296 p.

2. Vygodskiy L.S. Detskaya psikhologiya [Child Psychology]. Sobr. Soch. V6 T. T. 4 [Writings. In 6 vols. V1. 4]. Moscow, Pedagogika Publ., 1984. 432 p.

3. Giro P. Chastnaya i obshchestvennaya zhizn grekov [Private and Public Life of the Greeks]. Petrograd, Polyakovoy Publ., 1915. 687 p.

4. Deklaratsiya po problemam stareniya. Doklad Vsemirnoy assamblei po problemam stareniya, Vena, 26 iyulya - 6 avgusta 1982 goda (Izdanie Organizatsii Obyedinennykh Natsiy), glava $V I$ [The Declaration on Aging. Report of the World Assembly on Aging, Vienna, 26 July-6 August 1982 (United Nations Publication), Chapter VI]. URL: http:/ /www.un.org/ru/documents/decl_conv/declarations/ declold.shtml (accessed March 10, 2018).

5. Milyukov A.I. Opyt i uroki ekonomicheskikh reform v SSSR v 79-80-e gody [Experience and Lessons 
of Economic Reforms in the USSR in the 1979-1980s]. Gumanitarnye nauki. Vestnik Finansovogo universiteta, 2018. no. 2, pp. 17-24.

6. Ponamareva E.V. Reprezentatsiya obraza Donalda Trampa $\mathrm{v}$ britanskikh mediatekstakh politicheskoy napravlennosti [Representation of the Image of Donald Trump in British Media Texts of Political Orientation] Filologicheskie nauki. Voprosy teorii i praktiki, 2017, no. 10, pp. 143-147.

7. Porshnev B.F. Sotsialnaya psikhologiya $i$ istoriya [Social Psychology and History]. Moscow, Nauka Publ., 1979. 235 p.

8. Jung K.G. Issledovanie fenomenologii samosti. Aion [Study of the Phenomenology of the Self. Aion] Moscow, Refl-buk-Vakler Publ., 1999. $336 \mathrm{p}$.

9. Atella V., Carbonari L. Gerontocracy Harmful for Growth? A Comparative Study of Seven European Countries. Journal of Applied Economics, 2017, no. 20, pp.141-168.

10. Berton M.R., Panel S. Strategic gerontocracy: why nondemocratic systems produce older leaders. Public Choice, 2017, vol. 171, no. 3, pp. 409-427.

11. Bovenberg A.L. Grey New World: Europe on the Road to Gerontocracy? CESifo Economic Studies, 2008, vol. 54, no. 1, pp. 55-72.

12. Gilleard C. Old Age in Ancient Greece: Narratives of desire, narratives of disgust. Journal of Aging Studies, 2007, vol. 21, no. 1, pp. 81-92.

13. Kohli M., Arza C. The Political Economy of Pension Reform in Europe. Handbook of Aging and the Social Sciences. New York; London, Academic Press, 2011, pp. 251-264.

14. KompK. The Political Economy of the ThirdAge. Gerontology in the Era of the Third Age: Implications and Next Steps. New York; MA, Springer, 2011, pp. 51-66.

15. Gomez L.R., Gamaz A.B.P., Cordoba S.F., Villasana B.S. La gerontocracia y el consejo de ancianos. Península, 2013, vol. 8, no.1, pp. 7-24.

16. Wanasika J.P., Howell R., Littrell R., Dorfman R., Managerial P. Managerial Leadership and Culture in Sub-Saharan Africa. Journal of World Business, 2011, vol. 46, no. 2, pp. 234-241.

17. Sinn H.W. Pensions and the path to gerontocracy in Germany. European Journal of Political Economy, 2003, vol. 19, no. 1, pp. 153-158.

18. Torres-Gil F.M., Spencer-Suarez K. Aging electorates and gerontocracy: The politics of aging in a global world. International Handbook on Ageong and Public Policy. Oxford, University of Oxford Press, Edward Elgar Publishing, 2014, pp. 227-241.

19. Vauclair C.-M. Why Does National Income Inequality Make Older People Ill? The Journals of Gerontology: Series B. URL: https://doi.org/10.1093/ geronb/gbv102. (accessed May 4, 2018).

20. Weber M. Economy and Society. An Outline of Interpretive Sociology. Los Angeles; London, University of California Press, 1978. 635 p.

21. World Population Prospects The 2017. Revision Key Findings and Advance Tables. URL: https://esa.un.org/unpd/wpp/Publications/Files/ WPP2017_KeyFindings. (accessed March 3, 2018).

\section{Information about the Authors}

Elena M. Drinova, Candidate of Sciences (Philosophy), Associate Professor of Department of International Relations, Political Science and Regional Studies, Volgograd State University, Prosp. Universitetsky, 100, 400062 Volgograd, Russian Federation, edrinova@mail.ru, drinova_em@volsu.ru.

Sergey I. Morozov, Candidate of Sciences (Politics), Associate Professor of Department of International Relations, Political Science and Regional Studies, Volgograd State University, Prosp. Universitetsky, 100, 400062 Volgograd, Russian Federation, si.morozov@mail.ru.

\section{Информация об авторах}

Елена Михайловна Дринова, кандидат философских наук, доцент кафедры международных отношений, политологии и регионоведения, Волгоградский государственный университет, просп. Университетский, 100, 400062 г. Волгоград, Российская Федерация, edrinova@mail.ru, drinova_em@volsu.ru.

Сергей Иванович Морозов, кандидат политических наук, доцент кафедры международных отношений, политологии и регионоведения, Волгоградский государственный университет, просп. Университетский, 100, 400062 г. Волгоград, Российская Федерация, si.morozov@mail.ru. 